\title{
Effects of Chronic Haloperidol on Stress- and Stimulation-Induced Increases in Dopamine Release: Tests of the Depolarization Block Hypothesis
}

Mark A. Klitenick, Ph.D., Matthew T. Taber, B.A., and H. Christian Fibiger, Ph.D.

There is considerable neurophysiological evidence that chronically administered neuroleptics can, under certain circumstances, decrease the activity of mesencephalic dopaminergic neurons. This finding, referred to as depolarization inactivation or depolarization block, has led to the hypothesis that the delayed therapeutic effects of neuroleptic drugs are due to a gradual silencing of mesolimbic dopaminergic neurons. One prediction of depolarization inactivation is that dopamine neurons in this state should be resistant to activation by excitatory stimuli. As a test of this prediction, rats that had been treated chronically with either saline or haloperidol $(0.5 \mathrm{mg} / \mathrm{kg} \times$ 21 days) were exposed to either acute mild stress or electrical stimulation of the prelimbic region of the prefrontal cortex while extracellular levels of dopamine in the nucleus accumbens were monitored by in vivo microdialysis. A 10-minute exposure to acute stress via tail pinch increased dopamine release by $20 \%$ and $18 \%$ in the saline and haloperidol groups, respectively. Similarly, 20 minutes of cortical stimulation increased dopamine release by $51 \%$ and $56 \%$ in rats treated chronically with saline or haloperidol, respectively. These results indicate that contrary to a prediction of the depolarization block hypothesis, mesolimbic dopaminergic neurons can be activated in neuroleptic-treated animals.

[Neuropsychopharmacology 15:424-428, 1996]
KEY WORDS: Depolarization block; Dopamine; Electrical stimulation; Prefrontal cortex; Nucleus accumbens;

Schizophrenia; Stress

The delayed emergence of the antipsychotic effects of neuroleptics has been attributed to the gradual development of depolarization inactivation of mesencephalic dopamine- (DA) containing neurons (Bunney and Grace

From the Division of Neurological Sciences, Department of Psychiatry, University of British Columbia, Vancouver, British Columbia, Canada.

Address correspondence to: H. C. Fibiger, Division of Neurological Sciences, Department of Psychiatry, University of British Columbia, 2255 Wesbrook Mall, Vancouver, BC V6T 1Z3, Canada.

Present address for M.A. Klitenick: Trophix Pharmaceuticals, Inc., 40 Cragwood Road-Suite B, South Plainfield, NJ 07080.

Received October 13, 1995; revised December 29, 1995; accepted January 3, 1996.
1978). This model proposes that chronic administration of neuroleptics produces a profound decrement in the responsivity of the mesotelencephalic DA system (for review, see Grace 1992). Whereas acute administration of neuroleptics has been shown to increase both the number and firing rate of spontaneously active DA cells in the substantia nigra pars compacta ( $\mathrm{SNc}, \mathrm{A} 9)$ and ventral tegmental area (VTA, A10) and to increase extracellular concentrations of DA in the striatum (Imperato and DiChiara 1985; Zetterstrom et al. 1985), chronic neuroleptic administration can dramatically reduce the number of spontaneously active A9 and A10 DA neurons (Bunney and Grace 1978; Chiodo and Bunney 1983; Grace and Bunney 1986; White and Wang 1983). However, the results of several recent studies have not been consistent with the presence of depolarization block in DA neurons after chronic neuroleptic adminis- 
tration. Indeed, Mereu and colleagues $(1994,1995)$ have suggested that depolarization block may occur only in the presence of anesthesia. In addition, using in vivo microdialysis, several laboratories have failed to detect changes in basal, extracellular concentrations of striatal DA after chronic haloperidol treatment (Hernandez and Hoebel 1989; Moghaddam and Bunney 1993), although both increases (Zhang et al. 1989) and decreases (Ichikawa and Meltzer 1990, 1991) have also been reported. Moghaddam and Bunney (1993) also examined evoked release and found that chronic neuroleptic treatment reduced the magnitude of $\mathrm{K}^{+}$-stimulated DA release. This finding suggests that neuroleptic treatment may affect the responsivity of DA neurons to excitatory stimuli, even when basal DA is unaffected.

According to the depolarization block hypothesis, activation of excitatory afferents should not enhance neurotransmitter release from DA neurons (Grace 1992). As a test of this hypothesis, in the present experiments extracellular levels of DA in the nucleus accumbens (NAc) were monitored in haloperidol-treated rats during either acute mild stress or electrical stimulation of the prelimbic region of the prefrontal cortex (PFC; Sesack et al. 1989). Both of these stimuli have been previously shown to enhance the activity of the mesolimbic dopaminergic system (Abercrombie et al. 1989; Jedema and Moghaddam 1994; Taber and Fibiger 1995).

\section{SUBJECTS AND METHODS}

Thirty-four male Sprague-Dawley rats (Charles River Canada Inc., Quebec, Canada) weighing $210 \pm 15 \mathrm{~g}$ were group housed (4 rats/cage) in a light- (12 hour:12 hour light/dark cycle) and temperature-controlled environment with food and water available ad libitum. Animals were handled for approximately 5 minutes/ day for 5 days before the beginning of the experiment.

Rats were injected daily with haloperidol $(0.5 \mathrm{mg} / \mathrm{kg}$ SC) or saline between 0900 and 1100 hours for 21 days. On day 20, each rat was anesthetized with Equithesin $(3.0 \mathrm{ml} / \mathrm{kg})$ and stereotaxically implanted with a dialysis probe $(2.0 \mathrm{~mm}$ of active membrane) into the right NAc (AP: $3.6 \mathrm{~mm}$, L: $1.5 \mathrm{~mm}, \mathrm{~V}:-7.8 \mathrm{~mm}$ ) according to the atlas of Pellegrino et al. (1979). In 13 of the 34 rats, bipolar stimulating electrodes (MS303/2, Plastic Products) were also implanted bilaterally in the prelimbic region of the PFC (AP: $5.0 \mathrm{~mm}$, L: $2.4 \mathrm{~mm}$, V: $4.2 \mathrm{~mm}$, angled at $20^{\circ}$; Taber and Fibiger 1995). Subjects were then singly housed in clear Plexiglas cages for the remainder of the experiment. A final injection of either haloperidol or saline was given on day 21 , and dialysis experiments were conducted on day 22, 48 hours after surgery. A solution containing $\mathrm{CaCl}_{2}(1.3 \mathrm{mM}), \mathrm{MgCl}_{2}(1.0 \mathrm{mM}), \mathrm{KCl}$ (3.0 mM), $\mathrm{NaCl}(147 \mathrm{mM})$, and phosphate buffer $(1 \mathrm{mM}$, $\mathrm{pH}$ 7.4) was perfused through the dialysis probe at a rate of $5 \mu \mathrm{l} /$ minute. Fifty microliter samples of dialysate were automatically injected every 10 minutes, and the concentration of DA was measured using high performance liquid chromatography (HPLC) with electrochemical detection as previously described (Brown and Fibiger 1992). A stable baseline was established and defined as four samples with less than $10 \%$ variation.

In one experiment, rats $(n=21)$ were exposed for a 10-minute period to acute mild stress via application of a padded Hoffman tubing clamp (Fisher Scientific) near the base of the tail. Pressure was applied until displacement behaviors (i.e., digging, grooming, eating, or drinking) without vocalization were elicited. In another experiment, rats $(n=13)$ received electrical stimulation of the PFC, using parameters that have been shown to support self-stimulation (Phillips and Fibiger 1978) and consisted of a $60 \mathrm{~Hz}$ sine wave applied for 20 minutes ( $100 \mu \mathrm{A}$ for 0.5 second every 5 seconds) as previously described (Taber and Fibiger 1995). After the termination of stimulation (tail pinch or electrical stimulation), four to six additional 10-minute samples of dialysate were collected. The rats were then removed from their cages and killed with an overdose of chloral hydrate. Fifty-micron frozen sections of the brain were taken and stained with cresyl violet to confirm placements of the dialysis probes and stimulating electrodes. Neurochemical data were normalized to percent change from baseline and evaluated using one-way and two-way analysis of variance (ANOVA) with time as the repeated measure and the Huynh-Feldt correction for degrees of freedom. Student's $t$-test was used to compare basal levels of extracellular DA (fmol/sample) in chronic saline- and haloperidol-treated animals. The neurochemical data were also analyzed in terms of $\triangle \mathrm{fmol} / \mathrm{sample}$ for each animal by subtracting the average of three prestimulation baseline samples from the sample showing the peak stimulation effect (Day et al. 1994). These data were analyzed using Student's $t$-test.

\section{RESULTS}

There was no significant difference $(p=.378)$ between basal levels of accumbal DA in saline and chronic haloperidol treated animals (Table 1). Figure 1A shows that in rats treated chronically with saline, a 10-minute exposure to tail pinch resulted in a significant increase $(p<.05)$ in extracellular levels of DA in the NAc, which reached a maximum of $20 \%$ above baseline. In animals treated chronically with haloperidol, tail pinch increased DA levels to $18 \%$ above baseline $(p<.01)$ with a time course that was very similar to that observed in the saline-treated group. The increases in DA release did not differ significantly $(F<1)$ between the saline- and haloperidol-treated groups. Although basal levels of accumbal DA were $21 \%$ lower in rats treated chronically 
Table 1. Basal and Stimulated Extracellular Concentrations of DA in the NAc

\begin{tabular}{lcr}
\hline \multicolumn{1}{c}{ Treatment } & $\begin{array}{c}\text { Basal Concentrations } \\
\text { (fmol/sample) }\end{array}$ & $\begin{array}{c}\text { Magnitude of Evoked Release } \\
\text { ( } \mathbf{f m o l} \text { sample) }\end{array}$ \\
\hline Tail pinch & & $16.49 \pm 6.9$ \\
$\quad$ Saline $(n=10)$ & $49.6 \pm 8.0$ & $8.93 \pm 1.7$ \\
$\quad$ Haloperidol $(n=11)$ & $38.9 \pm 7.6$ & $23.35 \pm 6.9$ \\
Electrical stimulation & & $20.64 \pm 8.3$ \\
$\quad$ Saline $(n=7)$ & $43.9 \pm 9.6$ & \\
Haloperidol $(n=6)$ & $37.7 \pm 10.3$ & \\
\hline
\end{tabular}

Data represented as the mean \pm SEM. None of the differences between the saline- and haloperidol-treated animals are statistically significant.
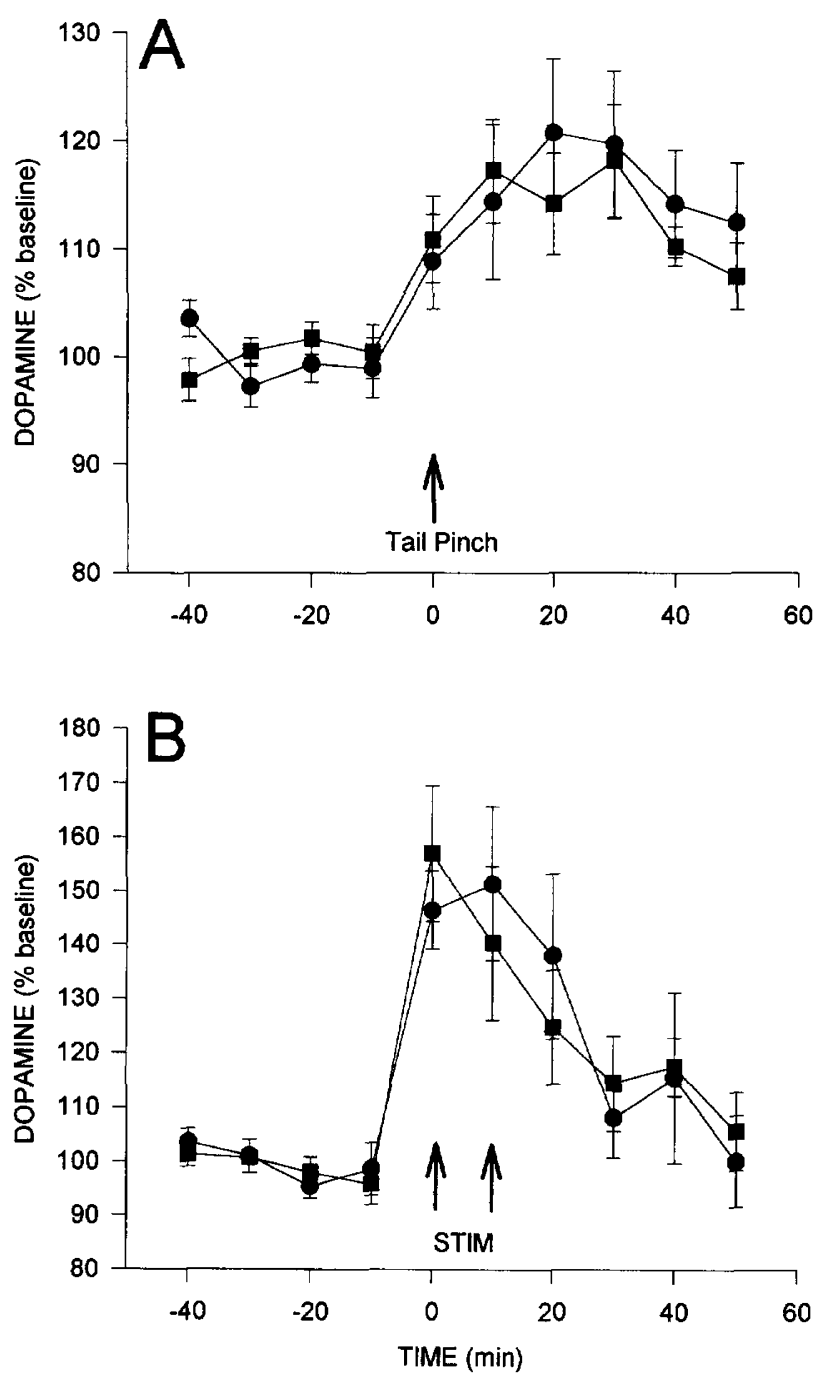

Figure 1. Effects of tail-pinch (A) or electrical stimulation of the PFC (B) on extracellular concentrations of DA in the NAc in rats treated chronically with saline (solid dots) or haloperidol (solid squares). Data represent the mean \pm SEM percent change from baseline. Note the difference in scale of the ordinates in (A) and (B). with haloperidol, there was no significant difference $(p=$ .324) between these groups in the absolute size of the evoked release of DA (Table 1).

Twenty minutes of electrical stimulation of the PFC resulted in a rapid increase in extracellular DA in the NAc in rats treated chronically with either saline or haloperidol (Figure 1B). In the chronic saline group, accumbal DA was significantly increased $(p<.01)$, reaching a maximum of $51 \%$ above baseline during the second 10 minutes of stimulation and gradually returned to baseline at 40 minutes after the stimulation period. Similarly, PFC stimulation in chronic haloperidol treated rats resulted in a significant increase in DA release $(p<.001)$. Levels of accumbal DA reached a maximum $56 \%$ above baseline during the first $10 \mathrm{~min}$ utes of stimulation and returned to baseline by $40 \mathrm{~min}-$ utes after stimulus termination. As with tail pinch, there was no significant difference between the control and haloperidol-treated rats $(F<1)$. Although basal levels of accumbal DA were $14 \%$ lower in haloperidol treated animals, the difference was not significant $(p=.658)$. In addition, analysis of the $\triangle \mathrm{fmol} / \mathrm{sample}$ measures indicated no significant difference between the groups $(p=$ $.806)$ in the absolute magnitude of evoked DA release.

Examination of the stained sections indicated placement of the dialysis probe through the dorsoventral extent of the NAc medial to the anterior commissure. Electrode tips terminated in the ventral aspect of the prelimbic region of the PFC as previously described (Taber and Fibiger 1995).

\section{DISCUSSION}

The present data demonstrate that acute mild stress produced by tail pinch and electrical stimulation of the PFC increase the concentrations of extracellular DA in the NAc of rats treated chronically with haloperidol. A small but significant increase of DA release was elicited with tail pinch stress, which persisted for 30 minutes after termination of stress. The magnitude of the increase was in the range previously reported after exposure to acute mild stress in untreated animals (Abercrombie et 
al. 1989; Carlson et al. 1991; Sorg and Kalivas 1991). Compared with controls, both the size of the increase and time course of DA release were similar in the saline- and haloperidol-treated rats. Electrical stimulation of the PFC resulted in an immediate increase in accumbal DA, corresponding to the period of stimulation, which then quickly returned to baseline levels. Again, this effect was similar in the control and haloperidoltreated rats.

In accordance with some previous findings (Hernandez and Hoebel 1989; Moghaddam and Bunney 1993), basal concentrations of extracellular DA were not altered significantly in the haloperidol-treated rats. Other groups have reported either decreased (Ichikawa and Meltzer 1990, 1991) or increased (Zhang et al. 1989) basal levels of DA in chronic haloperidol-treated animals. Although the basis for these divergent findings is uncertain, it is noteworthy that the studies reporting changes in DA concentrations after chronic neuroleptic treatment (Ichikawa and Meltzer 1990, 1991; Zhang et al. 1989) have used higher doses of neuroleptics than the studies finding no changes (Hernandez and Hoebel 1989; Moghaddam and Bunney 1993; present results). Whereas the differences in basal levels observed in the present experiments were not statistically significant, the haloperidol-treated animals did tend to have lower basal DA values. As has been pointed out previously (Day et al. 1994), nonsignificant group differences in basal concentrations in a dialysate have the potential of generating misleading conclusions when a treatment effect is expressed as a percent of baseline. Given the nonsignificant tendency for the haloperidol-treated animals to have lower baseline values, the effects of tail pinch and PFC stimulation were analyzed further in terms of the absolute increases in DA concentrations that were produced by tail pinch and PFC stimulation. This was calculated by subtracting the peak stimulation evoked increase from the average prestimulation baseline value ( $\triangle$ change in $\mathrm{fmol} / \mathrm{sample}$ ). In agreement with the percent baseline analysis (Figure 1), the absolute increase in DA release produced either by tail pinch stress or PFC stimulation did not differ significantly between the saline- and haloperidol- treated groups (Table 1).

Stress has long been known to exacerbate the symptoms of schizophrenia (Norman and Malla 1993). Animal studies have shown that stress can increase the metabolism and release of DA in cortical and subcortical areas (Abercrombie et al. 1989; Carlson et al. 1991; Fadda et al. 1978; Herman et al. 1982; Jedema and Moghaddam 1994; Morrow et al. 1993; Sorg and Kalivas 1991). In the context of the dopamine hypothesis of schizophrenia, these observations raise the possibility that stress-induced increases in DA release may contribute to the deleterious effects of stress in schizophrenic patients. If this is the case, then the depolarization block hypothesis would predict that chronic neuroleptics should attenuate stress-induced exacerbations in schizophrenia by attenuating stress-induced DA activation. In contrast to this prediction, chronic haloperidol did not impair the ability of tail pinch stress to increase DA release in the nucleus accumbens. This suggests that no aspect of the therapeutic efficacy of haloperidol is due to an attenuation of stress-induced activation of mesolimbic dopaminergic neurons.

Another prediction of the depolarization block hypothesis is that mesencephalic dopaminergic neurons that are in depolarization block should fail to be activated by excitatory inputs (Grace 1992). In view of the fact that we have recently demonstrated that stimulation of the PFC activates mesolimbic dopaminergic neurons via glutamate receptor mechanisms in the VTA (Taber et al. 1995), we tested this prediction by determining the extent to which chronic haloperidol attenuates PFC stimulation-evoked increases in DA release in the NAc. In accordance with the results obtained with tail pinch, chronic haloperidol failed to influence the ability of PFC stimulation to increase DA release in the NAc. This finding is at variance with a prediction of the depolarization block hypothesis and is consistent with the possibility that this phenomenon is best, and perhaps only, observed in anesthetized preparations (Mereu et al. 1995).

\section{ACKNOWLEDGMENTS}

This work was supported in part by the Medical Research Council of Canada and by an unrestricted grant from BristolMyers Squibb. We thank Catriona Wilson and Sheela Das for excellent technical assistance, and Charles Ashby, Jr. for helpful discussions.

\section{REFERENCES}

Abercrombie ED, Keefe KA, DiFrischia DS, Zigmond MJ (1989): Differential effect of stress on in vivo dopamine release in striatum, nucleus accumbens, and prefrontal cortex. J Neurochem 52:1655-1658

Brown EE, Fibiger HC (1992): Cocaine induced conditioned locomotion: Absence of associated increases in dopamine release. Neuroscience 48:621-629

Bunney BS, Grace AA (1978): Acute and chronic haloperidol treatment: Comparison of effects on nigral dopaminergic cell activity. Life Sci 23:1715-1728

Carlson JN, Fitzgerald LW, Keller RW, Glick SD (1991): Side and region dependent changes in dopamine activation with various duration of restraint stress. Brain Res 550:313-318

Chiodo LA, Bunney BS (1983): Typical and atypical neuroleptics: Differential effects of chronic administration on the activity of $\mathrm{A} 9$ and $\mathrm{A} 10$ midbrain dopaminergic neurons. J Neurosci 3:1607-1619

Day JC, Tham C-S, Fibiger HC (1994): Dopamine depletion 
attenuates amphetamine-induced increases of cortical acetylcholine release. Eur J Pharmacol 263:285-292.

Fadda F, Argiolas A, Melis MR, Tissari AH, Onali PL, Gessa GL (1978): Stress-induced increase in 3,4-dihydroxyphenylacetic acid (DOPAC) levels in the cerebral cortex and in N. accumbens: Reversal by diazepam. Life Sci 23:2219-2224

Grace AA (1992): The depolarization block hypothesis of neuroleptic action: Implications for the etiology and treatment of schizophrenia. J Neural Transm 36:91-131

Grace AA, Bunney BS (1986): Induction of depolarization block in midbrain dopamine neurons by repeated administration of haloperidol: Analysis using in vitro intracellular recording. J Pharmacol Exp Ther 238:1092-1100

Herman JP, Guillonneau D, Dantzer R, Scatton B, Semerdjiian-Rouquier L, LeMoal M (1982): Differential effects of inescapable footshocks and of stimuli previously paired with inescapable footshocks on dopamine turnover in cortical and limbic areas of the rat. Life Sci 30:2207-2214

Hernandez L, Hoebel BG (1989): Haloperidol given chronically decreases basal dopamine in the prefrontal cortex more than the striatum or nucleus accumbens as simultaneously measured by microdialysis. Brain Res Bull 22:763-769

Ichikawa J, Meltzer HY (1990): The effect of chronic clozapine and haloperidol on basal dopamine release and metabolism in rat striatum and nucleus accumbens studied by in vivo microdialysis. Eur J Pharmacol 176: 371-374

Ichikawa J, Meltzer HY (1991): Differential effects of repeated treatment with haloperidol and clozapine on dopamine release and metabolism in the striatum and nucleus accumbens. J Pharmacol Exp Ther 256:348-357

Imperato I, DiChiara G (1985): Dopamine release and metabolism in awake rats after systemic neuroleptics as studied by trans-striatal dialysis. J Neurosci 5:297-306

Jedema HP, Moghaddam B (1994): Glutamatergic control of dopamine release during stress in the rat prefrontal cortex. J Neurochem 63:785-788

Mereu G, Lilliu F, Vargiu P, Muntoni AL, Diana M, Gessa GL (1994): Failure of chronic haloperidol to induce depolarization inactivation of dopamine neurons in unanesthetized rats. Eur J Pharmacol 264:449-453

Mereu G, Lilliu V, Vargiu P, Muntoni AL, Diana M, Gessa GL
(1995): Depolarization inactivation of dopamine neurons: An artifact? J Neurosci 15:1144-1149

Moghaddam G, Bunney BS (1993): Depolarization inactivation of dopamine neurons: Terminal release characteristics. Synapse 14:195-200

Morrow BA, Clark WA, Roth RH (1993): Stress activation of mesocorticolimbic neurons: Effects of a glycine/NMDA receptor antagonist. Eur J Pharmacol 238:255-262

Norman RMG, Malla AK (1993): Stressful life events and schizophrenia I: A review of the research. Br J Psychiatry 162:161-166

Pellegrino LJ, Pellegrino AS, Cushman A (1979): A Stereotaxic Atlas of the Rat Brain. New York, Plenum

Phillips AG, Fibiger HC (1978): The role of dopamine in maintaining intracranial self-stimulation in the ventral tegmental area, nucleus accumbens, and prefrontal cortex. Can J Physiol 32:58-66

Sesack SR, Deutch AY, Roth RH, Bunney BS (1989): Topographical organization of the efferent projections of the medial prefrontal cortex in the rat: an anterograde tracttracing study with Phaseolus vulgaris leucoagglutinin. J Comp Neurol 290:213-242

Sorg BA, Kalivas PW (1991): Effects of cocaine and footshock stress on extracellular dopamine levels in the ventral striatum. Brain Res 559:29-36

Taber MT, Fibiger HC (1995): Electrical stimulation of the prefrontal cortex increases dopamine release in the nucleus accumbens of the rat: Modulation by metabotropic glutamate receptors. J Neurosci 15:3896-3904

Taber MT, Das S, Fibiger HC (1995): Cortical regulation of subcortical dopamine release: Mediation via the ventral tegmental area. J Neurochem 65:1407-1410

White FJ, Wang RY (1983): Comparison of the effects of chronic haloperidol treatment on A9 and A10 dopamine neurons in the rat. Life Sci 32:983-993

Zetterstrom T, Sharp T, Ungerstedt U (1985): Effect of neuroleptic drugs on striatal dopamine release and metabolism in the awake rat studies by intracerebral dialysis. Eur J Pharmacol 106:27-37

Zhang W, Tilson H, Stachowiak MK, Hong JS (1989) Repeated haloperidol administration changes basal release of striatal dopamine and subsequent response to haloperidol challenge. Brain Res 484:389-392 